\title{
The Blindness of Focusing. Pragmatic theories of communication and the challenge of validation
}

Sigmund Ongstad - sigmund.ongstad@hioa.no

Oslo and Akershus University College of Applied Sciences

My concern is that a preoccupation with the notion of validity of interpretation may blind us to a more basic notion, that of communication of interpretation (Catudal, 1990, p. 22)

\section{Abstract}

In this theoretical article it is argued that certain pragmatic approaches to language and communication are necessary to take into consideration when validating cultural, immanent 'objects' or cultural utterances. It is claimed that he very act of attention creates, as a direct co-effect, a problematic context. Hence, handling context is seen as crucial to validation as a process. So-called triadic theories of communication combine the three key aspects syntax, semantics, and pragmatics. It is argued that such theories offer perspectives and tools for analysing the dynamics of text and context, utterance and genre in different semiotic modes and channels. In the first part the concept of validity is discussed. Further some triadic theories are presented. Texts of Bakhtin and of Habermas on relations between a communicative (triadic) perspective and kinds of validities are discussed. A framework (a 'model') that integrates several of the discussed perspectives is then outlined and is used to clarify the concept of positioning. This concept is coined to enable combinations of more categorial (aspect dependent) and relational research designs. It is asked: Validating and/as positioning(s)? A brief example is given (just) to illustrate implications of a triadic perspective when working with validity. In the next main section some challenges, implications, and dilemmas are touched upon. The article ends suggesting that a double triadic framework of positioning has the potential to theorise validity claims connected to veracity, truth and normativity as well as critiquing possible weaknesses. By not just focusing figure (text or utterance), but even theorising ground (context or genre) and how the two relate, blindness might be reduced and validity increased.

Key words: Validities, contexts, communicational triads, discursive positioning, genres, semiotics.

\section{Clarifying the aim of the article}

What is meant by The blindness of focusing can be illustrated with an anecdote about Hegel. He was famous for being 'difficult'. One semester he surprisingly started gently by asking a very concrete question: - Can you see the blackboard? However as soon as the students nodded, relieved, his next question was: - But could you see your seeing? Of course, trying to direct one of the body's senses to pay specific attention will inevitable create lack of attention on the non-focused. In this sense most of us has only one mind each time. This kind of non-attentional 'blindness' for what is around the 'figure' holds for how we use language and semiotics as well and has basic consequences for the validity of any research. 
By simply focusing a particular communicational aspect in a cultural utterance other relevant aspects will be back-grounded. This inevitable split between figure and ground and thus text and context, will put validation at risk. In a sense co-text and context paradoxically are both established, and for the time being, 'killed' or postponed. Validation is challenging for several reasons. Firstly 'languaging' in itself implies (a forced) focusing. If nothing is uttered, minds of communicators will not be alerted. Secondly, by accepting a chosen focus as the research object, linguistic analysis risks being to be too narrow. Thirdly, the use of more open metaphors and general concepts challenges a more precise validation.

However, by rather seeing 'language' (in a strict sense) as an integrated part of semiotic cultural communication, it seems possible to establish the same validation (methodology) regime or framework for both the 'object' and for the researcher. The key point is 'position', from where it (communicationally) is focused, uttered or interpreted. Two theorists, especially, have developed a broad and specific communicative theory that can be applied when studying text/context dilemmas in culture and discourse, namely Jürgen Habermas and Michael Halliday (Habermas, 1984 \& 1988; Halliday, 1978 \& 1994). The use of the two theorists in this article should seen as Habermasian and Hallidayian though, as I will also refer to and lean on works of both successors and forerunners (Bühler, 1934; Martin, 1997). A main reason for choosing Habermas and Halliday is that they both have developed a systemic triadic view, the former on communication and the latter on language. Their theories seem relatively compatible as they both allow for integration into a broader semiotic framework. In addition the two can increase our principle understanding of validation (Habermas) and of context (Halliday). Although validation is a key concept in the title, the article is not about how to validate. The main focus (sic!) is to problematise some major implications of a paradigmatic move from a Saussurean dyadic view on language ('la langue') to a triadic, that is a communicational view on semiotics (Saussure, 1916; Nöth, 1990).

My first interest in these matters started in the early 1970s when pragmatists such as Austin and Searle tried to find a place for pragmatics between syntax and semantics, the two key constituents of what then was perceived as 'language' per se. How should one handle the logic of a triadic relationship between a structural form, a referential content and an addressive act, given that a dyadic logic had been commonplace in most research fields? The crucial methodological challenge of combining the two perspectives has still not and may not ever be 'solved'. Hence I am not claiming that a pragmatic communicational perspective represents a final way out of the dilemma (trilemma). However, if syntax, semantics, and pragmatics of (cultural and verbal) utterances are seen as working simultaneously, even validity needs to be inspected from the same (triadic, that is) communicational perspective.

For approaches such as text theory, genre theory, and discourse analysis a pragmatic extension is fundamental, necessary, and risky. Thus, to move methodologically from 'language' as a focused position to communication or semiotics, including pragmatics, will not make validation easier, but rather more complex and challenging.

\section{The meaning of meaning or the validation question}

Once a context can be declared 'dead', claiming that it has insignificant impact on the result, traditional validation can be more safely and formally applied by searching a possible statement that can be researched and in principle be clarified as false, or for the time being, not false (Popper, 1959). However, if context rises up from the dead after an in vain 'killing' (Bakhtin, 1986), validity is at risk. In the 1960 s E. D. Hirsch claimed, partly in opposition to Gadamer's famous work on truth and method, that the validity of a text-interpretation depends on what he termed the text's intrinsic genre (Hirsch, 1967; Gadamer, 1960). This concept seemingly refers to the particular mode in which a text or an utterance was (intentionally) given a more restricted meaning. Hirsch's claim that the 
concept of genre was crucial for validity was not followed up by other scholars during the 1970s. However, the necessity (or the problem) of genre became clearer when Bakhtin's seminal work on genre and utterance became popular in the late 1980s and early 1990s (Bakhtin, 1986). In the wake of his fame his work on validity in the 1920s came to surface as well (Bakhtin, 1993).

In a somewhat similar way one could argue that interpretation of utterances (texts) depends on the semiotic and triadic nature of the communicational macro concept that accompanies and coproduces utterances. This broadened and triadic view represents a general challenge to any qualitative research. The critical oppositions from Chronbach (1971), Cherryholmes (1993), Kvale (1989), Catudal (1990), Mishler (1990), Maxwell (1992) and Lather (1993) against traditional conceptions of validation in qualitative research are all relevant in this context. However, their views should be extended with a triadic semiotic approach when validating qualitative research. This holds not only for the positioning of the researched, the 'object', but even, as already argued, for the (implicit) positioning of the researcher (Fuchs, 1993). Triadic views on signs, utterances, texts, discourses, and genres can, among others, be found in the semiotics of Peirce (1940 \& 1994), Bakhtin (1986), Halliday (1978 \& 1994) and Habermas (1984). (See for instance Ongstad, 2014.)

Validation of communication implies evaluation of utterances. Taking a point of departure in a triadic concept of discursive positioning allows for a first overall validation related to reciprocity of the three constitutive dimensions of any verbal and cultural utterance: Expressive positioning ('focusing') favours structure and relates validity primarily to aesthetics or the nice-ugly dimension. Referential positioning favours content and relates validity primarily to epistemology or the true-false dimension. Finally addressive positioning favours action and relates validity primarily to ethics or the right-wrong dimension. By underlining primarily it is made clear that all aspects have to be taken into account when the utterance eventually will be interpreted as a whole.

Accordingly, the use of triadic approaches moves the question of validation from pure essentialism to the semiotic systemic and 'rhizomatic' complexity of research as blurred communication (Jahsonic, 2006; Deleuze \& Guattari, 1983). This is the case for any step in a semiotic process. For instance will research in/on education have to take several aspects of the communicational chain into consideration. They have all an impact on final validity: the student's inner genre (embodied context), the student's utterances, the observer's given inner embodied genres for perception, the researcher's way of observing and recording, the researcher's overall research design, the researcher's utterances and genres, and even the receiver's/the reader's inner genre system. Hence, to validate is to clarify the interplay of these stages of communication. To appeal to the safe protection of an established discipline, which obtains validity through prescribed, general methods of structural context-killing, can on the one hand bypass the researcher's validity problem. However, it may on the other hand not increase relevance for application in practice. Cherryholmes (1988) warns that researchers in any case have to trust a pragmatic validation of the speech act:

[...] because it is concerned with giving persuasive (pragmatically convincing) accounts of what is going on. Whether an argument or story (about construct validity and research) is persuasive or not is determined against the context and background of communities of researchers, communities under investigation, and possible alternative communities (Cherryholmes, 1988, p. 128).

Thus validity depends on the risky balance of the totality of semiotic meanings and positionings of all affected (semiotic) products and processes. Any interpretation of any utterance is thus forced to relate to the blurred aesthetic, epistemic, and ethic shifts of communication. In these shift genre is crucial to validity of interpretations, but since genre according to this hypothesis has become embodied and complex, validity is still at risk. Similarly Jonathan Culler has stated: - Meaning is context bound, but context is boundless (Culler, 1981, p. 24). However, seeing cultural communication as dynamic (triadic) embodied genres should make context both less dead and less 
boundless. Such a paradigmatic shift might challenge our traditional configurations of validity, but it should also broaden our understanding of the rhizomatic nature of communicational complexities without being too paralysed by them.

Nevertheless, there are sciences, disciplines, subjects, and methods that strive, and should strive to achieve a high level of traditional validity. For any structuralist approach this is a main and even necessary goal. Saussure's dyadic definition of the sign, his segregation between 'la langue' and 'la parole', Hjelmslev's purifying of his approach by formalising semantics, Tarski's and Carnap's logics, Chomsky's generative grammar and Popper's differentiation in three possible worlds, are all classical grips to try obtain analytic control and to reduce communication to pure 'objects' by leaving out 'irrelevant' context. This procedure will be adequate in scientific fields such as mathematics and chemistry, but it can only be achieved by destroying or dismantling real communication and meaning. In analyses of cultural utterances a traditional concept of validity tends to be inadequate, especially if culture is reduced by structural methodological grips to restricted signs (as purified 'objects'). Therefore, it is in the following necessary to investigate different crucial relationships between signs, utterances, and communication.

\section{Triadic approaches to sign, utterance, and communication}

\section{Bühler's communicational sign triad}

Bühler's classic sign concept is seen as a communicational triad. He developed what he called an organon model (Bühler, 1934). The use of the Greek word 'organon' hints that language is seen as $a$ means, not just as a system or as dyadic opposition between a signifier and a signified, as we find in Saussure's influential work (Saussure, 1916). Bühler's functional approach puts him in some sense in line with later pragmatists, such as Wittgenstein, Austin, Searle, and Halliday. They all stressed language as use, in other words a functional or a pragmatic view. According to Bühler there are three characteristic, overarching, and integrated functions of language and of signs in general:

representation, expression, and appeal, respectively related to objects, sender, and receiver. Focusing any one of these aspects gives that particular function dominance. Hence the sign works as a symbol when the representative function dominates, as a symptom when expression dominates, and as a signal when appeal dominates. All aspects are at work at the same time in any communication and use of signs (Bühler, 1934, p. 28; Nöth, 1990, p. 185). This triadic understanding is in other word an implicit definition of communication, as different from language in a more restricted sense.

\section{Bakhtin's view of the triadic utterance}

While Bühler was sign-oriented, Bakhtin was text-oriented. Bakhtin (1986) left behind the Saussurean sign-dyad (signified/signified) in favour of the semiotic, triadic communicational utterance, which he conceptualized as a mixture of products and processes:

- delimiting (from former utterances)

- positioning (the utterance as such by...)

- expressing

- referring a semantic content

- addressing

- finalising (the utterance as a whole by...)

- finalising forms

- semantic exhausting

- ending speech will (by which expressivity becomes a first constitutive aspect)

(by which referentiality becomes a second constitutive aspect)

(by which addressivity becomes the third constitutive aspect)

(by which form as aspect contributes to wholeness) (by which content as aspect contributes to wholeness) (by which intention as aspect contributes/establishes wholeness) 
It should be underlined that the three steps delimiting, positioning, and finalising are not forming a triad (Ongstad, 2004). They are just sequences in a chain of communicational utterances through time. Expressing, referring and addressing however are real triads as they are parallel, integrative, inseparable, reciprocal, and simultaneous processes. Bakhtin (1986) hinted that even genres should be seen as triadic, but did not theorise the idea much further. However a double triadic view of text and context (utterance and genre) can be found in the work others.

\section{Hallidayian view on text and context as triadic}

While one may find triadic perceptions of signs, texts, utterances and communication in the works of Aristotle, Dewey (1916), Harré (1980, 1984 \& 1991), Habermas (1984), Baumann (1995) and many others, rather few have related the question of triads to the level of genre/discourse/context (Miller, 1984; Halliday, 1978 \& 1994; Bakhtin 1986; Fairclough, 1992; Martin, 1997, Ongstad, 2002a \& 2002b, Togeby, 2014). According to Hallidayians (or Systemic Functional Linguistics, SFL) language has three meta-functions: ideational, interpersonal and textual, and their function and relationship should be understood as follows:

Ideational resources are concerned with representation, interpersonal resources with interaction and textual resources with information flow. In SFL this intrinsic functional organization is projected on to context, redounding with the variables of field, tenor and mode - where field focuses on institutional practices, tenor on social relations and mode on channel (Martin, 1997, p. 4).

SFL's coined concepts will not be discussed here. The main idea should be stressed though: according to this way of thinking, language is a (triadic) realization of social context and vice versa, social context comprises patterns of language that are perceived through a triadic system (Lemke, 1995). In other words, constitutive aspects in utterances (texts) and genres (contexts) correspond systemically and behave like a system. This basic standpoint seems to match Bakhtin's triadic understanding of utterance outlined above (and thus perhaps even genre). Therefore, one can simplify the metaphorical framework to consist of six (two times three) major aspects, in-between which discursive positionings have to take place:

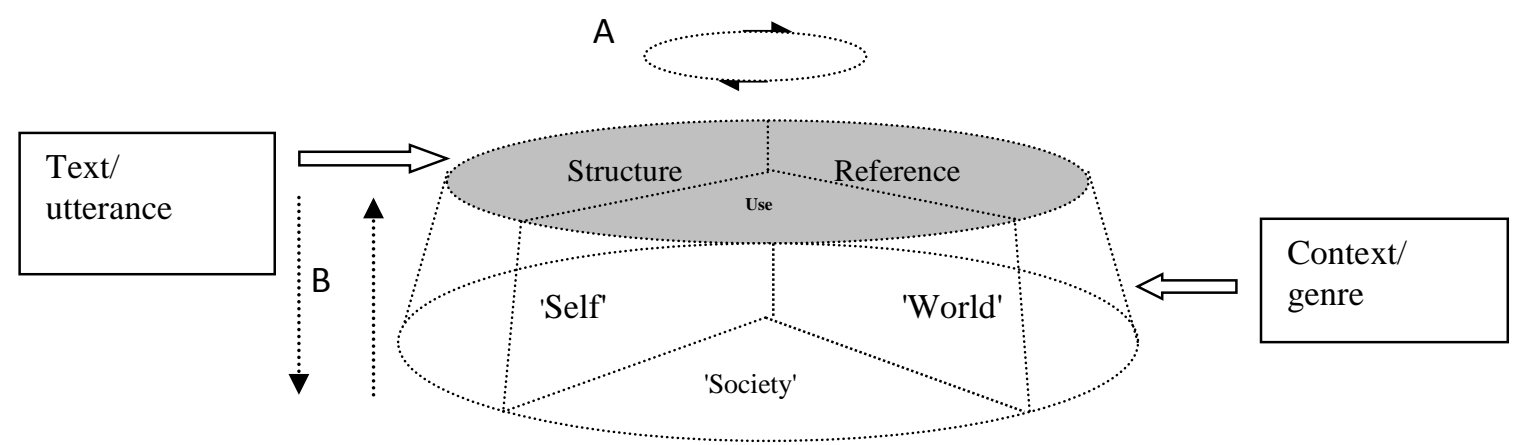

Figure 1. The relationship between the three major aspects on the concrete level of utterance/text (the grey 'surface') and the respective three major aspects of the immanent level of embodied context/genre. 'A' represents the process of constant mixing of horizontal (in the moment) key aspects when uttering. ' $B$ ' represents the double process of using genres (over time) both as a resource while uttering and interpreting, and the process (over time) of extending this resource system whenever communicating. According to this view a crucial part of 'context' is seen as embodied/learned genres/discourses. There are only dotted lines, which indicates that in principle there are no fixed categories, only interrelated, dynamic, systemic aspects. These aspects will relate to each other both vertically and horizontally (syntactically and parataxically). 
To summarise and to relate main concepts: The aspects form, content, and use are the basic and necessary constituents of both utterance and genre. A somewhat more precise set than the above concepts, often used in schools, could be (respectively) structure, reference, and act. As pointed to earlier emotionality and aesthetics are primarily related to structured form. We search for essence and epistemological meaning in referential content, and efficiency and ethics in used acts. These aspects, when evaluated, consciously or not, establish, again respectively, the fields of aesthetics, epistemology, and ethics. Saying fields implies seeing them paradoxically as both focused and separate, back-grounding other potential ways of describing them. At the same time though, they should be seen as communicatively closely related fields, providing resources for establishing analytic wholeness of meaning.

These aspects can, still respectively, be connected to a further division of a person's lifeworld in three major dimensions: aesthetics related to self, epistemology to world and ethics to society (Habermas, 1984). However, they will all be mutually related and there will mostly be no clear-cut division between them as they interact during processes of uttering and interpretation. Validating in these three intertwined fields and dimensions is respectively related to what is more traditionally referred to as subjectivity, objectivity, and normativity. Again, these are aspects with no clear discursive borders. All aspects are systemically related to each other, although positioning or discursive focusing may put each of them mentally for the time being in the forefront. A focused, interpretative dominant is established or directs the process of uttering or the process of uptake or interpreting (Jakobson, 1960).

The almost never-ending search for problems connected to these three main philosophical fields (and their inner relationship) probably originates from or are related to Kant's three famous critiques of judgement, pure reason, and practical reason in which he discussed premises for aesthetics, epistemology, and ethics. Critique should here be understood as analysis or inquiry. Kant wanted on the one hand to treat these aspects strictly separate: "We can reduce all the powers of the human mind, without exception, to these three: the cognitive power, the feeling of pleasure and displeasure, and the power of desire (...) to bring unity into that diversity of powers (...) is futile (Kant, 1987, pp. 394-395)." On the other hand the three key aspects can nevertheless be seen as a set:

In conclusion, then, it is indeed the power of judgment, but above all the aesthetic power of judgement, i.e. the power of judgement as unaided by reason, that is responsible for the mediation between the "world" of the first Critique and the "world" of the second Critique by which the three Critiques come to form a system (Pluhar, 1987, p. civ).

It should be mentioned that scholars such as Karl Bühler, Rudolf Steiner, Michael Bakhtin, and Jürgen Habermas, as well as several others have been concerned with this Kantian puzzle. To conclude, Kantian critique (Kant, 1987), commonsense evaluation, and research based validation of aesthetic, epistemological, and ethical aspects of cultural utterances are closely related enterprises. But how closely related are texts' form, content, and use, on the one hand, and philosophers' search for balancing complexities of the validity claims veracity, truth, and fairness on the other hand? Combining Bakhtin and Habermas may give an answer.

\section{Bakhtin and Habermas on communication and validation}

For validating the implications of the triadic view on the utterance according to Bakhtin are:

There is no aesthetic ought, scientific ought, and - beside them - an ethical ought; there is only that which is aesthetically, theoretically, socially valid, and these validities may be joined by the ought, for which all of them are instrumental. These positings gain their validity within an aesthetic, a scientific, or a sociological unity: the ought gains its validity within the unity of my once-current answerable life (Bakhtin, 1993, p. 5, my underlining). 
This thinking needs to be related to a larger framework. Habermas (1984) proposes a triadic view on communication, on lifeworld, and on validity that will have paradigmatic implications for all kinds of research and methodology. He sees utterances as related to three integrated worlds, to the subjective worlds which are all experiences to which each communicator has privileged access, further to the objective worlds, about which there can be made true statements, an finally to the social worlds which consist of all interpersonal relations (Habermas, 1984, p. 100). All these aspects and their relations will inevitably be triadic. He holds that to the three different structural components of the lifeworld, which he calls culture, society, and personality, there correspond three reproduction processes which are (respectively) termed cultural reproduction, social integration, and socialization.

These components and processes stem from different aspects of communicative action, which are seen as understanding, coordination, sociation. They are all rooted in the structural components of speech acts, which in speech act theory are called propositional, illocutionary, and expressive. "These structural correspondences permit communicative action to perform its different functions and serve as a suitable medium for the symbolic reproduction of the lifeworld (Habermas 1984, p. xxv/McCarthy (Translator's introduction)".

\begin{tabular}{|c|c|c|c|}
\hline \multirow{2}{*}{\multicolumn{4}{|c|}{$\begin{array}{l}\text { Aspect of lifeworld } \\
\text { Form of appearance }\end{array}$}} \\
\hline & & & \\
\hline for reality relations & subjectivity & objectivity & normativity \\
\hline Speech acts & expressive & propositional & illocutionary \\
\hline General functions & experiences & matters & relations \\
\hline Mode & expressive & cognitive & interactive \\
\hline Speech act & representative & constative & regulative \\
\hline Theme & utterer's intention & propositional content & interpersonal relation \\
\hline Validity claim & truthfulness/veracity & truth & fairness, usefulness \\
\hline Components of the lifeworld & personality & culture & society \\
\hline Reproduction processes & socialization & cultural reproduction & social integration \\
\hline Communicative action & sociation & understanding & coordination \\
\hline
\end{tabular}

$\overline{\text { Figure 2. Communicational triads according to Habermas (1984). }}$

Habermas has further claimed that many triads are related to each other in a systemic way ('horizontally' and 'vertically') and thus creates a network of triads. Validity of (Bühlerian) symptoms can hence be understood as to which degree the expressed is in accordance with the utterer's inner emotions and intentions, in other words the (estimated) quality of subjectivity. Further validity of symbols can be seen as to which degree the phenomena referred to can be judged as true or false, in other words the degree of 'objectivity'. Finally the validity of signals can be interpreted as to which degree the utterance is pragmatically sound, that is, right or wrong (as action) for more than the utterer, in other words the quality of normativity (or degree of intersubjectivity). A main point then, is that none of these three extremes can occur as pure categories; utterances are placed in-between. They are placed within the triadic communicational space, and by the same token, so are validities. This holds both for (Habermasian) components and processes. Validity thus concerns both entities and processes.

Bühler's triad is the direct source and point of departure for Habermas. In the article, Toward a Critique of the Theory of Meaning, he underlines the value of a validity-theoretic interpretation of Bühler's functional scheme (Habermas, 1998). The main aspects of utterances are, as we have seen, the form/structure, the content/ reference, and the use/act. Depending on where one positions the research focus, and accordingly the 'object', one faces different validity expectations. Regarding this 
'trilemmatic' dilemma of choice/selection Habermas claims that the "(...) validity-theoretical interpretation of Bühler's functional scheme offers itself as a way out of the difficulties of speech-act theory because it does justice to all the three aspects of a speaker coming to an understanding with another person about something (Habermas 1998, p. 73 \& p. 76)". He further points out that a validity-theoretic interpretation of Bühler's functional scheme further leads to the assumption that "(...) with a speech act an utterer takes up relations simultaneously to something in the objective world, to something in the subjective world and to something in the social world (Habermas 1998, p. 73 \& p. 76, Habermas' own italics)."

Accepting such a (triadic) simultaneity is to take on a logic of three (a triadic and thus communicational thinking) and will provoke any traditional validation regime which will try to build only on a dyadic, digital, dual, and/or structural thinking. This crucial and inevitable question will be discussed towards the end. Here I might help demystifying the digit of the triadic three. 'Translated' into more traditional terms Bühler's triad equals or parallels a traditional triad of form, content, and use, notions traditionally used about text in many language textbooks in Mother Tongue Education in schools. Hence a sign, an utterance, a text, a genre, a discourse, a context, in short, any communication and communicational element, will have a structural form, a referential content, and an addressive use. These are always intertwined, mutual, parallel and simultaneous, which in practice means that meaning is established and real communication happens within and by means of this dynamic triangle.

Or in other words, the triadic mutuality functions as the very definition of communication. They are three, and not two, five or seven, or ( $n$ ), because three is the lowest possible number of aspects necessary to establish or define communication (as different from 'language' as a system or a category): Someone says or utters (by form) something (content) to someone (use). The three elements are not categories, but dynamic aspects or 'vectors' signalling what may be dominant. They create, cooperatively, a semiotic 'universe' within which utterers and interpreters must communicate or take into consideration, if they want to communicate. Knowledge of form, content, and use are resources taken from the embodied semiotic system that each communicator (utterer and interpreter) will bring to communication. In Habermasian terms these are embodied as components by communicational processes. In addition it should be underlined that any communication can break down, for instance if any of the three constituents does not work.

The simple framework of (two times three) aspects I have presented above does not allow for an either/or paradigm. It should rather be seen as a way of illustrating paradoxical conflicts of both/and between dyads and triads, in other words, between (dyadic) language and (triadic) communication as phenomena and concepts. Humans using eyes and language will focus, create a 'figure', but utterances, communication, and mind help us (normally) to establish sufficient 'wholeness' or meaning, a balance and synthesis of all relevant aspects.

Thus I agree with Habermas that the social, that is the pragmatic dimension, or the intersubjective/society/you, has to be brought into a triadic framework along with the traditional linguistic aspects form and content (syntax and semantics). One should be careful when confronted with strongly antagonistic, dyadic, polarised approaches, such as for example 'psycho-socio' or 'socio-cognitive' perspectives, by handling pairs of two separately. This is especially the case where a third might be missing. Cf. works with titles such Aestethics and Logic (Holmgaard, 1999/ SO's translation), Aesthetics and Ethics (Levinson, 1998), and Morality and Objectivity (Honderich, 1985).

However in cultural fields, for instance disciplinary didactics, such as Science Education and Language Education, an overall approach may benefit from applying a triadic framework. In other words when communication of meaning tends to be secondary, dyadic referential understanding of validity may be, not only relevant, but even necessary. It is nevertheless hard to find any mental, human activity that does not have or may have a communicational aspect. As hinted in the introduction: Not only is 
social life identical with communication, but all communication (and hence all genuine social life) is educative (Dewey, 1916, p. 5).

The paradox occurs when bringing together dyadic and triadic thinking. For instance trying to make dyadic Saussurean and triadic Hallidayian grammar compatible will be confusing to many, and hard to sort out. Further Bakhtin sees dialogues as never-ending chains of communication and utterances and genres as triadic. This view should not necessarily be seen as an inconsistency. It could rather be seen as genuine Bakhtinian openness, irrespectively the fact that Bakhtin himself never addressed the logic of the dilemmatic trilemma explicitly (Ongstad, 2004). The key to understanding im-/ balances is the thought-provoking principle of simultaneity (Habermas, 1998). Expressivity, referentiality, and addressivity in utterances, and accordingly aesthetics, epistemology, and ethics are reciprocal (Ongstad, 2002a \& 2002b). Bakhtinian dialogism could therefore be seen as dynamics between the aspects and their infinite sub-variations on the one hand and dynamics between the triadic utterance and the triadic genre on the other hand.

\section{Validating and/as positioning(s)?}

If we evaluate, let us say the aesthetic aspect, we also need to take the epistemological and ethical aspects of communication into consideration, since all the three are interrelated. References, content, and knowledge are surveyed, explicitly or implicitly, by a sort of logical true-false regime. Further utterances as acts are considered ethically as good-bad/fair-unfair. Hence validation is a question of balancing three inseparable, though analytically separated, major kinds of communication at once (Ongstad, 2014). Depending on which main aspect will be the point of departure or focused, one will, according to Habermas, have to relate simultaneously to truthfulness/veracity, truth, and fairness/usefulness. Hence, it will be the context that in the end will help guiding us to see which aspects are ir-/relevant, once something is focused (as text or object). However, since context is systemic and dynamic through the impact of embodied genres and immanent genre processes, we are usually dependent on an intricate genre resource system to make sense of and sort out the interplay between text and context, utterance and genre, cultural object and discourse.

This can be illustrated, by borrowing from S'aenz-Ludlow (2003) the intimate balance both between the main aspects and between concrete utterances and anticipated genres (contexts) with the following three utterances:

1. Student: "I hate mathematics!"

2. Student: "The total sum for all whole numbers from 1 to 100 is 5050."

3. Student: "I will sum up all numbers from 1 to 100 by using the calculator."

In context 1 we may understand the utterance as strong expressivity and interpret it as an emotional statement, based on the verb hate and the use of exclamation mark. We even have to consider whether the student actually means it, how truthful the utterance is, that is to interpret the veracity of the emotional expression. In practical research we are dependent on the truthfulness of our informants - how do we make it seem likely to readers that someone we quote is honest? We need to consider whether the utterance is at face value. In context 2 we perhaps would tend to ask: Is it true? and try to calculate it or back up the claim using the mathematical genre called proof. In context 3 we might, as mathematicians and math teachers, consider the functional value of using the calculator, what Habermas terms usefulness.

However, all three validities/aspects/dimensions are still present in each of the three utterances. What we do by giving priority to or focusing one particular aspect that seems to be dominant, is implicitly to position the utterance. It happens by interpreting the context as a certain mathematical and/or communicational genre or discourse. Professional, disciplinary, and common-sense genre knowledge may thus help us to understand the validity balances (or imbalances) between 
subjectivity, objectivity, and normativity (= intersubjectivity). However, these three aspects are general types, not delimited categories (Ongstad, 2014). In real communication they appear as differentiated, blurred and unique/specific. By positioning all three aspects we therefore at once

a) take a position, a point of view, a perspective,

b) focus, creating an imagined, fixated object,

c) take for granted an un-uttered context/genre that will help the utterance to give a fuller or sufficiently finalised meaning, to use Bakhtin's concept.

\section{Implications and challenges}

\section{Relevance for generalizing versus applied sciences}

Research in for example science, sociology, and linguistics tends to prioritise research objects and methodological procedures that at the end of the day are mostly supposed to contribute theoretically to that discipline by making valid generalisations that can develop the discipline/science. Applied sciences or professions, on the contrary, may aim at using established general, disciplinary knowledge to solve or sort out specific problems and challenges. Particular fields, such as research on communication in educational settings, may nevertheless find themselves squeezed between these two basic ways of logical reasoning. Induction-/deduction-regimes are established within many scientific disciplines, by stressing Popperian falsification regimes for validation. Such formal regimes may in some cases obstruct possibilities for developing a more holistic or general understanding of the many aspects of the phenomenon in question.

There is also a need for educators to apply suggestive interpretations, that is, a deliberate undecided balance of, and reciprocity between, theory and practice. This is to move abductive thinking (or dynamic hypothesis-building as a continuous process) to the forefront of research processes.

Linguistics and other 'hard' sciences, such as mathematics or chemistry, are designed to deliver tools for explaining carefully, stringently delimited phenomena, as scientifically focused 'things' or 'objects' (Ongstad, 2006). Educators who work with human beings, with learning, and with meaning, need tools and methodologies to improve the understanding of how parts relates to wholeness. Working in an applied field nevertheless leaves one with a basic dilemma between part and whole, categories and relations, essence and connectedness, closed and open, the challenge of the hermeneutic circle.

\section{Epistemology versus relativism}

According to Sokal and Bricmont much postmodern discourse flirts with different forms of cognitive relativism, especially in academic humanities and social sciences, which they find rooted, among others, in the influential work of Kuhn and Feyerabend. What they find at stake and at risk is epistemology as such, and a main problem, they claim, is relativism:

Roughly speaking, we shall use the term 'relativism' to designate any philosophy that claims that the truth or falsity of a statement is relative to an individual or to a social group. One may distinguish different forms of relativism according to the nature of the statement in question: cognitive or epistemic relativism when one is dealing with an assertion of fact (that is, about what exists or is claimed to exist); moral or ethical relativism when one is dealing with a value judgement (about what is good or bad, desirable or pernicious); and aesthetic relativism when one is dealing with an artistic judgement (about what is beautiful or ugly, pleasant or unpleasant) (Sokal \& Bricmont, 1999, pp. 50-51/my use of cursive).

This implicit triadic view on kinds of relativism makes sense from the perspective of communication as triadic. The aesthetic is related to form and structure of the utterance or the object. The epistemic 
or cognitive is related to the utterance, the sign or the object as content or reference. Finally the moral or the ethical is related to the researched phenomenon as a possible act. This triad will be discussed again later. It is first necessary to problematise the methods of closing of certain meanings.

\section{The closed versus the open}

Instead of following Sokal and Bricmont's critique of Kuhn and Feyerabend I will contrast their concerns with a quote from Luce Irigaray, who was one of the critiqued 'postmodernists'. Irigaray, as a defence, tries to pinpoint the basic concerns in what she terms 'the mathematical sciences', which seem not to be just mathematics:

(...) the mathematical sciences, in the theory of wholes [théorie des ensambles], concern themselves with closed and open spaces, with the infinitely big and the infinitely small. They concern themselves very little with the question of the partially open, with wholes that are not clearly delineated [ensembles flous], of the passage between, of fluctuations occurring between thresholds of specific wholes. Even if topology suggests these questions, it emphasizes what closes rather than what resists all circularity (Irigaray, 1985, p. 315/Sokal \& Bricmont, 1999, pp. 110-111).

Just to rephrase a point of view here: Sciences dealing with 'nature' as objects need procedures that create a delimitable object. Research methods in some sciences try to achieve this through a move that can be called "adequate closure". Sciences and disciplines studying 'culture' (which is cultural 'communicative') need to take into consideration that their objects hardly ever can be fully, only partially closed. Closing or fixation will on the one hand leave out, in Irigaray's terms, the partially open and the borders between, but on the other hand make arguments and proofs 'democratically' open to everyone by the rules of the game. By comparing mathematical and natural language one could say that mathematics is an 'unnatural' language invented to prevent the possibility for making 'lies'. As a contrast so-called natural, verbal language may, in Umberto Eco's terms, be defined as the very tool by which one in principle can make or actually has to make 'lies' (Eco, 1984).

In a methodological perspective all researchers have to decide about the closed and the open, counting closed quantities and/or interpreting open qualities. The kind of semiotics, for instance, using chemical, mathematical or linguistic/verbal signs influences the rules of this game. Moving from formal linguistics to communicational theories of utterances, genres and discourses may change the game from searching closed categories that can be falsified to revealing partly open aspects that should be interpreted. A major challenge is in this perspective to decide what is most important for validation, the sign as a category or genre as a relational system. They are both necessary for validation, each in their own way.

\section{Peirceian 'interpretant' versus Habermasian 'communication'}

Before discussing the opposition of the two concepts one should know that Peirce's perception of sign is dynamic, as contrast to Saussure's more fixed understanding (by opposing the signified and the signifier). It is especially the concept interpretant that makes Peirce's semiotics an open enterprise. However, he has not developed any genre or discourse theory, and has not paid much interest in the social aspects of sign-making. In his book Postmetaphysical Thinking Jürgen Habermas in an article on Peirce and Communication, therefore raises the following question:

What considerations could have induced Peirce to turn away from the intersubjective aspects of the sign process? I want to defend the thesis that the interpretant relation of the sign cannot be explained without recourse to the conditions for reaching an intersubjective agreement, however rudimentary these conditions may be (Habermas, 1998/1988, p. 92).

In concluding, Habermas holds that the legacy of Platonism is in fact repeated in Peirce's work, even if Peirce obviously takes an anti-Platonist standpoint: 
Both allow communication, in which tendency to universialisation asserts itself, to be seen from only one side: communication is not for the sake of reaching mutual understanding between ego and alter about something in the world; rather, interpretation only exists for the sake of representation and the ever more comprehensive representation of reality. This privileging of the sign's representative relation to the world above the sign's communicative relation to the interpreter causes the full-fledged interpreter to disappear behind the depersonalized interpretant (Habermas, 1998/1988, p. 9).

What is at stake then in social sciences, the humanities, and educational research is a choice or conflict between Plato, Saussure, and Chomsky on the one hand focusing reference, or Peirce or Gadamer focusing interpretation of parts that cannot easily be fixed on the other hand. Or is there a third choice? In the first part of his article (p. 92) Habermas points to the fact that the young Peirce actually worked with the idea of writing a book about the interplay and the dynamics of 'I', 'Thou', and 'It' as "Elements of thought" (intended book title). However he did not stick to the idea. Habermas suggests that this is the closest Peirce comes to a communicative/inter-subjective understanding of semiotics, in spite the fact that Peirce also has meant that "all thoughts were addressed to a second person" (the so-called doctrine of Tuism) (Habermas, 1998/1988, p. 111, note 3).

What is at risk in much cultural and educational research is meaning. If that is supposed to be closed essence, an essence that in turn contributes significantly to categories in an established generalising science or discipline such as pure linguistics or classical sociology, the interpretant seemingly needs to be configured or understood as closed, as an entity that can be clarified. If meaning is complex, a composite, the interpretant needs to be kept open as it is likely to be affected by different aspects of the utterance, and of genre and discourse as context.

\section{Bridging the gap by positioning as a framework?}

There are several implications of the view presented above: Firstly, concepts are connected systemically, that is system-like, not yet fully closed. Secondly, the framework is relational, that is, all concepts/aspects are in some way related, created by communication as a network of dynamic aspects. Thirdly, the concepts in question are aspects, not categories. Hence one needs a specific focus to do research, that can relate the figure, the ground, and the basis for perspective within a connected framework. The concept positioning is coined to try achieve a relational combination (Ongstad, 1997 and 2007; Smidt, 2007; and Braathe, 2005).

Positioning is thus a process and a product (positioning(s) in which sign-users locate their uttering selves (and all possible sub-aspects related to this key aspect), their perceived worlds (and any phenomenon that can be sub-ordinated to this key aspect), and their relation to others (and any social sub-aspects connected to this key aspect) semiotically in cultural utterances. The processes and the products are framed and structured by the impact of embodied meaning resources, by genres, which should be seen as meaning resources. Uttering then has, in principle, in order to function as communication, constantly to use and to move between expressing the uttering self, referring the world, and addressing others. Hence in the processes of uttering a self, a world, and a society is established as fully and intricately integrated, as lifeworld in a Habermasian sense.

If and when we focus, and our interest is language, a focused object can be figured as text. What is not looked at, but immediately connected to it, is the background for the focused figure. This is the context, and it is established by the very act of focusing. Contexts vary from immediate to distanced and quite a few concepts and metaphors have been used to characterize and to differentiate aspects or kinds of contexts, such as co-text, cultural context, register, and genre. A way to avoid or omit a negative discussion of terms is simply to talk about a micro and a macro level, where the micro level 
represents the focused object, the figure, and where the macro level represents the co-working background (Ongstad, 2002b).

A main reason why these two levels or aspects should be seen in explicit connection is that meaning is not only developed exclusively within a text or an utterance, but is even a product of interplay of what is explicitly said and implicitly unsaid. Hence genres help their users by reducing and presupposing what needs to be/not to be in a text. The tacit expectations in the genre that help utterers to say more than they actually do, can be seen as ideologies, as hidden, but functional values and resources for communication in society, cultures, and disciplines. I may use Ricoeur to explain ideology: "An ideology is operative and thematic. It operates behinds our backs rather than appearing as a theme before our eyes. We think from it rather than about it (Ricoeur, 1981, p. 227)".

Although a reporter, an observer, an inspector or a researcher does not follow some kind of ideal expected receiver role, or originally is perceived of as a direct addressee by the sender/utterer, his or her observational position is nevertheless a receiver's in the sense that the utterance is primarily related to, even by observers, as meaning (or symbol in Bühler's term). Given a triadic view on communication (text - context) it is therefore no sense, within such a model, in giving the researcher a protected position outside this communication. In other words, research or observation becomes just another genre focusing or giving priority to utterance as 'world' or as an object from the 'world' embracing the focusing. With Cherryholmes: "How are we to read the genre we call research? Cherryholmes (1993, p. 2)."

\section{Validation as weighing the role of micro and macro aspects}

A double triadic view of semiotic communication (see figure 1) implies that the researcher not only accepts the focused figure (the utterance) as partly open, but recognises the reciprocal role of genre/discourse/context in this openness. Hence researchers should investigate the shift in the triadic balance between structure, reference, and action when they in the ongoing work and their presentation of their work as they document, argue, present, compare, comment, evaluate, claim, refer, admit, hypothesize, discuss, suggest, define, problematise, operationalise, exemplify, focus, abduce, indicate, exclude, illustrate, show, etc. All these speech acts, verbs, functions, and processes, may, when repeated, structured and formalised, take on a role as particular research genres and discourses. Such genres create the rules for the interplay between what is traditionally called subjectivity, objectivity, and intersubjectivity. This dynamics is at the very heart of validation. Researchers need to understand the implications of each of these implicit acts and approaches. With Steinar Kvale: To Validate Is to Question and To Validate Is to Theorize (Kvale, 1989, p. 77). Kvale further argues: "In communicative and pragmatic approaches to validation, the context and community of the conversation and action are decisive. The truth of an interpretation is communicated and negotiated among people who share decisions and actions (Kvale, 1989, p. 88)."

\section{A brief bullet-point evaluation of a double triadic framework}

\section{From theory to empirical studies}

I have presented the ideas consequently as theory without any reference to empirical studies. The article is indeed theoretical and focuses validation on a general level. This does not mean that the framework exists entirely as theory. Empirical studies based on the framework can be found elsewhere, for instance in: Ongstad (1997) studying schools' task culture and autobiography, Ongstad (1999) studying a student's self-positioning, Ongstad (2002b, 2004, \& 2005) researching writing, Ongstad (2006, 2010, \& 2012a) focusing what in Scandinavia is termed disciplinary didactics, for example mathematical education and language education. In Ongstad (2007) I investigate Positioning in/of Practice. On communication and validation. Some works are written in Norwegian, some in English. In a recent publication (Ongstad, 2014) I have collected nine articles written in English where 
the framework is applied. So far I have been advocating mainly benefits of combining key communicative triads rather single-mindedly. In the following and as a conclusion I pinpoint some advantages and pitfalls.

\section{A double triadic, semiotic framework may (...)}

- enable an integration of theories of self, world, and society

- be a useful tool to explain the rise and decline of cultures and subcultures

- function as a frame of reference for the problem of the hermeneutic circle

- allow specific and practical research (and pedagogical thinking) on positioning(s)

- be useful for comparative studies of communication and cultures

- give better access to the studies of power (genre gate-keeping)

- help understanding the subtle role-giving (and role-avoidance) in the use of genre

- be used for (self-)critique of ideologies (thus this triadic framework is relativistic)

- be basic for the understanding of life-long and institutional socialisation

- be crucial for any practical or theoretical question about validation

- work as a platform for discussing methodologies

\section{Advantages and challenges using analysis of positioning(s) as approach}

- keep principle elements in communication and education together and separate

- strengthen the possibilities to compare or integrate 'self', 'world', and 'society'

- open up for interdisciplinary and cross-scientific understanding

- be used by researchers, teachers and students as analysis and a way of understanding

- use the same approach for the observed, the object, and the observer

- balance aesthetics, epistemology, and ethics within a systemic/relational framework

- the different parts of the analyses may be inconsistent

- one may end up with banalities or uninteresting details

- a certain danger for categorial interpretation, even with a relational point of departure

- semiotic analysis beyond the sign level is still not well developed

- detailed analysis is more time-and-resource-consuming

- traditional approaches to validity may be challenging

\section{Key points concerning validities within a double triadic framework}

- form, content, and act challenge respectively veracity, truth, and fairness in utterances

- by researching utterers' intention, propositional content, and interpersonal relation in utterances, we are (respectively) making validity claims about truthfulness/veracity, truth, and fairness/usefulness

- genres balance combinations of subjectivity, objectivity, and intersubjectivity in utterances

- there exist systems of genres which differentiate subjectivities, objectivities, and intersubjectivities in utterances

- different genres give different premises for expressivity and hence veracity in utterances

- different genres give different premises for referenciality and hence truth in utterances

- different genres give different premises for addressivity and hence fairness in utterances

- different speech acts (verbs) such as document, argue, present, compare, comment, evaluate, claim, refer, admit, hypothesize, discuss, suggest, define, problematise, operationalise, exemplify, focus, abduce, indicate, exclude, illustrate, show, etc. give different premises for balancing expressivity, referenciality, and addressivity in utterances 


\section{Acknowledgements}

I would like to thank both reviewers for fair and clear scholarly reviews and very valuable comments. Especially I am grateful for one of the reviewers' many constructive suggestions on form, content, and function. Their reading has contributed significantly to necessary improvement of the manuscript. It should also be mentioned that different versions of the part Triadic approaches (...) have appeared in other contributions, for instance in Ongstad (2002b, 2004, 2005, and 2007).

\section{Literature}

Bakhtin, M. (1986). Speech Genres and Other Late Essays. Austin: University of Texas Press. Bakhtin, M. (1993). Toward a Philosophy of the Act. Austin: University of Texas Press. Baumann, Z. (1995/1993). Postmodern Etik. [Postmodern Ethics.] Gothenburg: Daidalos. Bourdieu, P. (1989). Outline of a Theory of Practice. Cambridge.

Braathe, H. J. (2005). Analysis of Positioning of Student Teachers' Identities in Their Mathematics Educational Texts. In Hudson, B. and Enser, K. (eds.) Researching the Teaching and Learning of Mathematics. Linz: Trauner Verlag.

Bühler, K. (1934/1965). Sprachtheorie. Stuttgart: Fischer.

Catudal, F. (1990). Validity, Communication, and Interpretation. Educational Philosophy and Theory. V. 22/2. Pp. 8-25.

Cherryholmes, C. (1988). Power and Criticism. Poststructural Investigations in Education. New York/London: Teachers College Press.

Cherryholmes, C. (1993). Reading research. Journal of Curriculum Studies, 25/1. Pp. 1-32.

Chronbach, L. (1971). Test Validation. In Thorndike, R. (ed.) Educational Measurement. Washington, DC: American Council of Education. Pp. 443-507.

Culler, J. (1981). The Pursuit of Signs: Semiotics, Literature, Deconstruction. Ithaca: Cornell University Press.

Deleuze, G. \& Guattari, F. (1983). On the Line. New York: Semiotext(e).

Dewey, J. (1916). Democracy and Education. New York: The Macmillan Company.

Eco, U. (1984). Semiotics of the philosophy of language. Bloomington: Indiana University Press.

Fairclough, N. (1992). Discourse and Social Change. Cambridge, UK: Polity Press.

Fuchs, S. (1993). Three Sociological Epistemologies. Sociological Perspectives, 36/1. Pp. 23-44.

Gadamer, H.-G. (1960/1990). Wahrheit und Methode. Tübingen: J.C.B. Mohr.

Habermas, J. (1984). The Theory of Communicative Action. (Vol. 1.) Boston: Beacon. (Transl. T. McCarthy.)

Habermas, J. (1998). Postmetaphysical Thinking. Cambridge, UK: Polity Press.

Halliday, MAK (1978). Language as social semiotic. London: Arnold.

Halliday, MAK (1994). An Introduction to Functional Grammar. Second Edition. London: Arnold.

Harré, R. (1980). Social Being. Totowa: Rowman and Littlefield.

Harré, R. (1984). Personal Being. Cambridge: Harvard University Press.

Harré, R. (1991). Physical Being. Oxford: Blackwell.

Hirsch, E. D. (1967). Validity in Interpretation. New Haven: Yale University Press.

Holmgaard, J. (ed.) (1999). AEstetik og logik. Ålborg: Center for AEstetik og Logik/Medusa.

Honderich, T. (ed.) (1985). Morality and Objectivity. London: Routledge.

Irigaray, L. (1985). Parler n'est jamais neutre. Paris: Éditions de Minuit.

Jahsonic (2006). Vocabulary of culture: Rhizome. www.jahsonic.com.

Jakobson, R. (1960). Closing Statements: Linguistics and Poetics. In Sebeok, T. A. (ed.) Style In Language, Cambridge Massachusetts: MIT Press. Pp. 350-377.

Kant, I. (1987/1790). Critique of Judgment. Indianapolis: Hackett Publishing Company.

Kvale, S. (ed.) (1989). Issues of Validity in Qualitative Research. Lund: Studentlitteratur.

Lather, P. (1993). Fertile Obsession: Validity After Poststructuralism. The Sociological Quarterly, 34/4. Pp. 673-693. 
Lemke, J. (1995). Textual Politics. Discourse and Social Dynamics. London: Taylor and Francis.

Levinson, J. (1998). Introduction: aesthetics and ethics. In Levinson, J. (ed.) Aesthetics and Ethics. Essays in the Intersection. Cambridge: Cambridge University Press. Pp. 1-25.

Martin, J. R. (1997). Analysing genre: Functional parameters. In Christie, F. \& Martin, J. (eds.) Genre and Institutions. Social Processes in the Workplace and School. London: Cassell. Pp. 3-39.

Maxwell, J. (1992). Understanding and Validity in Qualitative Research. Harvard Educational Review. 62/3: Pp. 279-300.

Miller, C. R. (1984). Genre as social action. Quarterly Journal of Speech, 70. Pp. 151-67.

Mishler, M. (1990). Validation in Inquiry-Guided Research: The Role of Exemplars in Narrative Studies. Harvard Educational Review. 60/4. Pp. 415-443.

Nöth, W. (1990). Handbook of Semiotics. Bloomington: Indiana University Press.

Ongstad, S. (1997). Sjanger, posisjonering og oppgaveideologier. Et teoretisk-empirisk bidrag til et tverrfaglig, semiotisk og didaktisk sjangerbegrep. Ph.d.-thesis. Trondheim: NTNU.

Ongstad, S. (1999). Self-positioning(s) and students' task reflexivity - a semiotic macro concept exemplified. Journal of Structural Learning \& Intelligent Systems, vol. 14(2). Pp. 125-152.

Ongstad, S. (2002a). Genres - from static, closed, extrinsic, verbal dyads to dynamic, open, intrinsic semiotic triads. In R. Coe et al. (eds.) The Rhetoric and Ideology of Genre: Strategies for Stability and Change. Hampton Press. Pp. 297-320.

Ongstad, S. (2002b). Positioning Early Norwegian Research on Writing. Written Communication 19/3. Pp. 345-381.

Ongstad, S. (2004). Bakhtin's triadic epistemology and ideologies of dialogism. In Bostad, F., Brandist, C., Evensen, L. S. \& Faber, S. (eds.) Bakhtinian perspectives on language and culture: Meaning in language, art and new media. London: Palgrave Macmillan. Pp. 65-88.

Ongstad, S. (2005). Enculturation to institutionalized writing - meaning making in a triadic semiotic perspective? In Kostouli, T. (ed.) Writing in Context(s). Textual practices and learning processes on sociocultural settings. New York: Springer. Pp. 49-67.

Ongstad, S. (2006). Mathematics and Mathematics Education - Language and/or Communication? Triadic Semiotics Exemplified. Educational Studies in Mathematics. 61/1. Pp. 247-277.

Ongstad, S. (2007). Positioning in/of Practice. On communication and validation. In Herrlitz, W., Ongstad, S. \& Ven, P. H. v. d. (eds.) Research on mother tongue education in a comparative international perspective. Theoretical and methodological issues.. Amsterdam: Rodopi. Pp. 181-210.

Ongstad, S. (2010). Synchronic-diachronic Perspectives on Genre Systemness: Exemplifying Genrification of Curricular Goals. In Kvam. S. et al (eds.) Genre and Cultural Competence: An Interdisciplinary Approach to the Study of Texts. Berlin: Waxmann. Pp. 35-50.

Ongstad, S. (2012). Fra kunnskap, via kontekst, kjerne og komparasjon til kommunikasjon. En fagdidaktisk utviklingslinje? Nordidactica - Journal of Humanities and Social Science Education 2012:2. http://kau. divaportal.org/smash/record.jsf?pid=diva2:417293

Ongstad, S. (2014). Disciplinarity and/as Communication. Discursive and semiotic perspectives on education. Oslo: Oslo and Akershus University College of Applied Sciences.

Peirce, C. S. (1940/65). Collected Papers. Cambridge, Mass.: Belknep Press.

Peirce, C. S. (1994). Semiotik og pragmatisme. Copenhagen: Gyldendal.

Pluhar, W. (1987). Translator's Introduction. In Kant, I.: Critique of Judgment. Indianapolis: Hackett Publishing Company. Pp. xxiii-cix.

Popper, K. (1959). The Logic of Scientific Discovery. New York: Basic Books.

Ricoeur, P. (1981). Hermeneutics and the Human Sciences. Cambridge: Cambridge University Press.

S'aenz-Ludlow, A. (2003). Classroom mathematics discourse as an evolving interpreting game. In

Anderson, M., S'aenz-Ludlow, M., \& Cifarelli, V. (eds.) Educational Perspectives on

Mathematics as Semiosis: From Thinking to Interpreting to Knowing. Legas Press: Ottawa. Pp. 253-284.

Saussure, F. de (1916/1974). Course in General Linguistics. (By J. Culler.) London: Fontana.

Sokal, A. \& Bricmont, J. (1999). (2nd ed.) Intellectual Impostures. London: Profile books. 
Smidt, J. (2007). Positioning, responsibility, and relevance in MTE research. In Herrlitz, W., Ongstad, S. \& Ven, P. H. v. d. (eds.) Research on mother tongue education in a comparative international perspective. Theoretical and methodological issues. Amsterdam: Rodopi. Pp. 211-226.

Togeby, O. (2014). A Model of Text Types and Genres. In Engberg, J., Maier, C. D. \& Togeby, O. (eds.) Reflections upon Genre. Encounters between Literature, Knowledge, and Emerging Communicative Conventions. Tübingen: Narr Verlag. Pp. 147-176. 